\title{
REFLEXÕES SOBRE O ENSINO DE PROJETO DO PONTO DE VISTA DA GESTÃO DO CONHECIMENTO
}

Cassia Mousinho de Figueiredo

Universidade Veiga de Almeida

cassiafigueiredo@hotmail.com

Resumo: O desenvolvimento de novos produtos, serviços e processos é uma atividade que requer dos projetistas grande quantidade de informação e capacidade criativa para chegar às soluções mais adequadas ao contexto. Neste artigo é realizada uma aproximação entre o projeto, especialmente no âmbito do ensino, e os conceitos da Gestão do Conhecimento. A reflexão proposta busca levar a uma melhor compreensão dos processos de aquisição de informação e de conversão do conhecimento entre professor, aluno e outras fontes relacionadas. Essas reflexões nortearam o desenvolvimento de diversas atividades de solução de problemas realizadas com estudantes de graduação em Design e Engenharia com pouca ou nenhuma experiência em projeto, cujo modelo de aplicação é apresentado neste trabalho.

Palavras-chave: design de produto, ensino de projeto, gestão do conhecimento

\begin{abstract}
The development of new products, services and processes is an activity that requires the designers great deal of information and creative ability to reach the most appropriate solutions to the context. This paper presents an approach between design, especially in education, and the concepts of the Knowledge Management. The proposed reflection seeks lead to a better understanding of information acquisition processes and conversion of knowledge among teacher, student and other related sources. These reflections guided the development of several problemsolving activities with Design and Engineering students with little or none experience in project, whose application model is presented in this paper.
\end{abstract}

Keywords: product design, design education knowledge, management 


\section{INTRODUÇÃO}

O design é de natureza multidisciplinar e como profissão e campo de estudo veio da necessidade de conciliar diferentes saberes na prática profissional. A Escola de Ulm, com o propósito de aproximar os estudantes das práticas de mercado, agregou os saberes de disciplinas como Economia, Administração, Sociologia, Ciência Política (BURDEK, 2006). Seguindo a essência multidisciplinar do design, cujos limites se expandem constantemente, este artigo tem por objetivo estabelecer uma relação entre duas áreas de diferentes saberes para promover uma reflexão sobre o ensino de projeto a partir do foco da Gestão do Conhecimento. Dessa reflexão, realizada pelo grupo de pesquisa Projeto: Criatividade e Inovação, foram pensadas diversas atividades de caráter projetual para aplicação nos primeiros períodos da graduação de Design e de Engenharia. Nesse trabalho serão apresentados os aspectos básicos que norteiam tais atividades para melhor ilustrar os argumentos.

A atividade de projeto de um novo produto, serviço ou processo demanda boa parte de seu tempo na busca por informações que levem a soluções adequadas para os problemas definidos. As bruscas e constantes mudanças no mercado e na sociedade nos levam a buscar meios de capacitação orientados para um contexto no qual o conhecimento se torna algo valioso. O conhecimento vem sendo estudado com mais interesse desde os anos 1990, especialmente por pesquisadores e profissionais de áreas ligadas a questões de competitividade e estrutura das organizações, como a Administração e a Engenharia de Produção. Por isso a maior parte dos estudos associa o conhecimento à criação de valor e à vantagem competitiva das organizações, mas esses conceitos têm total aderência com a capacitação de profissionais para o projeto.

Para a reflexão proposta, será abordado o modo como a informação e o conhecimento são transmitidos aos alunos a partir dos princípios dos quatro modos de conversão do conhecimento desenvolvido por Nonaka e Takeuchi (1997). No próximo item serão apresentados alguns conceitos da Gestão do Conhecimento pertinentes a esse estudo, como os tipos de conhecimento e os processos de conversão, realizados a partir de revisão bibliográfica. Em seguida, esses conceitos serão relacionados a alguns dos aspectos e necessidades do ensino de projeto. Por fim, para ilustrar essa discussão, será apresentado o modelo que norteia as atividades de solução de problemas que são realizadas com alunos de design e engenharia. Esse modelo foi baseado no conceito de aquisição de informação e nos modos de conversão.

\section{GESTÃO DO CONHECIMENTO}

Gestão do conhecimento é uma disciplina que se refere à criação, organização, recuperação, integração, conversão e compartilhamento do conhecimento de diversas formas em uma organização, para o profissional e também no âmbito acadêmico. Muitos autores afirmam que não há uma definição universal para a gestão do conhecimento, e a maioria deles a relaciona à vantagem competitiva e ao conjunto de ações que as organizações desempenham para gerenciar seus ativos tácitos (BUSCH, 2008). Sveiby (1998) a apresenta como a arte de criar valor a partir da gestão dos seus ativos intangíveis e dos fluxos de conhecimento.

Nessa área do saber, há alguns termos que precisam ser compreendidos. O que muitas vezes é chamado conhecimento codificado não é necessariamente conhecimento, mas informação. Informação, conhecimento e dado não são sinônimos. Dados são fatos objetivos ou observações, desorganizados, não-processados e não- 
contextualizados. São exemplos de dados: textos, fotos, figuras, sons gravados e animação, pois todos podem ser quantificados a ponto de se ter eventualmente dificuldade de distinguir a sua reprodução, a partir da representação quantificada, com o original (SETZER, 2001). Por não serem contextualizados, os dados se tornam irrelevantes para o projeto. Se os dados são organizados ou estruturados, convertemse em informação, que passa a ter relevância para um propósito ou contexto específico.

Informação é uma abstração informal que está na mente de alguém, representando algo significativo para essa pessoa. Já o conhecimento é geralmente relacionado à informação. Conhecimento é uma abstração interior, pessoal, de algo que foi experimentado ou vivenciado por alguém. Sendo assim, o conhecimento não pode ser descrito; o que se descreve é a informação. O conhecimento nasce como resultado da elaboração consciente das informações, que são a sua matéria-prima e a forma pela qual os conhecimentos se comunicam e são armazenados. Em outras palavras, ele não se torna conhecimento até que o receptor compreenda o que está sendo transmitido. É preciso haver contextualização e compreensão para se dizer que é conhecimento (SETZER, 2001). O conceito de informação está próximo do conceito de conhecimento, mas também diz respeito a interpretação e explicitação de ideias. Por outro lado, para produzir informação a partir do conhecimento, temos que interpretar o que vivenciamos e tornar explícito o que sabemos (DAHLBOM; MATHIASSEN, 1999 apud BUSCH, 2008).

A Gestão do conhecimento tem também outras abordagens, como a possibilidade de se reter, recuperar, organizar e reutilizar o conhecimento. Alguns autores já estudaram a organização do conhecimento no design. Teixeira et al. (2010) desenvolveram um instrumento para centralizar as informações do projeto e arquivar os processos decisórios que fazem parte deste. Muller (2001) propôs uma estrutura para uso em âmbito acadêmico, com o objetivo de facilitar o acesso a projetos acadêmicos anteriores através da classificação. Figueiredo (2013) desenvolveu uma ferramenta para recuperação, organização e disponibilização de conhecimento gerado em projetos anteriores para auxiliar a geração de novas soluções.

Neste trabalho serão enfatizados os conceitos referentes aos tipos de conhecimento, seus modos de conversão e a aquisição de informação necessária para o projeto. Numa abordagem semelhante, Fornasier e Emidio (2008) estudaram os modos de conversão do conhecimento na estrutura curricular de um curso superior de Moda. Naveiro (2011) relacionou os conceitos de Gestão do Conhecimento no projeto de carros para competição desenvolvidos por estudantes de graduação em Engenharia.

\subsection{Conhecimento explícito e conhecimento tácito}

$\mathrm{Na}$ Gestão do Conhecimento, divide-se o conhecimento em explícito e tácito. $\mathrm{O}$ conhecimento explícito é definido como aquele que é facilmente externalizado e codificado em palavras, textos, gráficos ou fórmulas. Já o conhecimento tácito é essencialmente o oposto do conhecimento codificado: é um conhecimento subjetivo, relacionado às habilidades, crenças e experiências do indivíduo (BUSCH, 2008). O conhecimento explícito é relativamente fácil de organizar e compartilhar, mas depende de vários fatores para ser absorvido pelo receptor. Como exemplo de conhecimento tácito pode-se citar o saber de um marceneiro, que aprendeu e 
aprimorou seu ofício através de anos de prática, observação e orientação. Seu conhecimento é implícito, e por isso é difícil transmiti-lo. Em outras palavras, Setzer (2001) aponta o conhecimento tácito como aquele que é mais fortemente baseado na compreensão individual, na experiência ou na vivência do indivíduo. Nonaka (1991) complementa essa definição:

"O conhecimento tácito também se encontra profundamente arraigado na ação e no comprometimento do indivíduo com determinado contexto - ou seja, o ofício ou a profissão, o mercado de certa tecnologia ou produto e as atividades de um grupo ou equipe de trabalho. O conhecimento tácito consiste em parte de habilidades técnicas - o tipo de destreza informal e de difícil especificação, incorporada ao termo know-how. O mestre artesão, depois de anos de experiência, desenvolve uma perícia profunda na 'ponta dos dedos'. Mas, em geral, é incapaz de explicitar os princípios científicos ou técnicos subjacentes à sua capacidade" (NONAKA, 1991, p. 3).

É por isso que não se 'ensina' a projetar. Esse é o conhecimento tácito do professor, resultante da sua experiência somada à sua vivência, observação, estudo. 0 que o professor faz é promover um contexto de aprendizagem, recorrendo a materiais que trazem o conhecimento explicitado como um apoio ou a dinâmicas para explicitar esse conhecimento. E para que o ciclo se complete é necessário que haja interesse por parte do estudante.

\subsection{Modos de conversão do conhecimento}

Nonaka e Takeuchi (1997) apontam quatro modos de conversão do conhecimento, derivados da interação entre conhecimento tácito e explícito: (1) socialização, de conhecimento tácito para tácito; (2) externalização, de conhecimento tácito em conhecimento explícito; (3) combinação, de conhecimento explícito em conhecimento explícito; e (4) internalização, que é a conversão do conhecimento explícito para tácito (Figura 1).

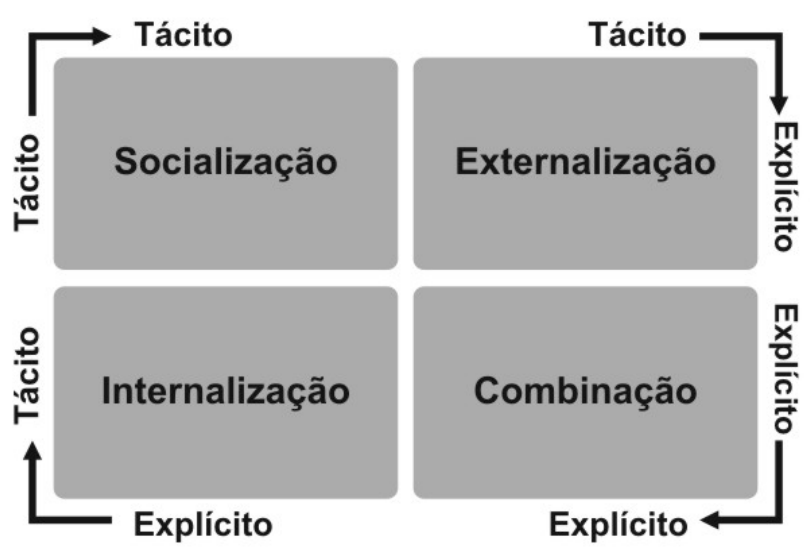

Figura 1: Quatro modos de conversão do conhecimento Fonte: Adaptado de NONAKA; TAKEUCHI, 1997

Os quatro modos de conversão serão vistos mais detalhadamente a seguir:

Socialização (tácito $\rightarrow$ tácito): como foi visto, o conhecimento tácito é difícil de ser expressado, mas há situações em que pode ser compartilhado entre duas ou mais pessoas. Esse modo de conversão é muito bem representado pelas figuras do mestre e 
do aprendiz. Nesse caso o aprendiz absorve habilidades do mestre. Por exemplo, o estudante atuando como aprendiz num escritório aprende por meio da observação, da imitação, da prática, e fazendo associações com a orientação do mestre. Com o tempo esse conhecimento se torna tácito para o estudante.

Combinação (explícito $\rightarrow$ explícito): as pessoas também são capazes de combinar componentes isolados do conhecimento explícito para a formação de um novo conhecimento. Um exemplo de combinação é quando os estudantes fazem um levantamento bibliográfico e o apresentam para o professor em forma de relatório. Esse documento é um novo conhecimento, pois sintetiza as informações de várias fontes. No entanto, essa combinação não amplia a base de conhecimento já existente para o estudante.

Externalização (tácito $\rightarrow$ explícito): quando o mestre é capaz de expressar seu conhecimento tácito sobre o seu ofício, ele o converte em conhecimento explícito. Tal conhecimento pode ser compartilhado de diversas formas, como os livros, tutoriais, aulas teóricas, fundamentação, etc. É um processo bastante conhecido pelos professores.

Internalização (explícito $\rightarrow$ tácito): o conhecimento explícito pode ser compartilhado, seja numa organização ou na sala de aula, e os profissionais ou estudantes o utilizam para ampliar, estender e reformular seu próprio conhecimento tácito. No ambiente educacional o conhecimento explícito compartilhado pelo professor é passível de internalização, ou seja, de acordo com o contexto, os alunos podem convertê-lo em conhecimento tácito.

Cabe ressaltar que não há um conhecimento melhor do que o outro, nem mesmo quando se refere a projeto. Tampouco há um processo de conversão mais adequado. Cada etapa do projeto demanda conhecimentos e processos de conversão específicos a sua natureza e finalidade, como será visto adiante.

\section{ENSINO DE PROJETO}

Uma das questões que mais levantam discussões acerca do ensino nos cursos superiores - especialmente aqueles que têm o projeto como base - é a distância entre a teoria e a prática, que faz com que os alunos cheguem ao mercado de trabalho um tanto despreparados para a realidade profissional. Esta proximidade é buscada desde a Bauhaus, em 1919, que não logrou sucesso nessa empreitada. Sua sucessora, a Escola de Ulm, de 1953, tentou reduzir essa distância, fazendo parcerias com empresas e levando professores de diferentes áreas para apoiar a multidisciplinaridade (CARDOSO, 2008). Maldonado (1991), um de seus diretores, frequentemente abordava a crescente distância entre a idealização e a execução, entre o projeto e o trabalho, mas confiava que no futuro essa distância seria drasticamente reduzida.

Bonsiepe (2012) tece muitas críticas ao ensino universitário, afirmando que seu objetivo principal é o de acumular conhecimentos. O autor argumenta que o ensino para desenvolver capacidade para resolver problemas deve praticar o know-how, e utiliza um exemplo: "A universidade proporciona hoje, ao estudante, a competência para escrever uma tese de $\mathrm{PhD}$ sobre natação, porém não lhe proporciona o knowhow de nadar". Para ele, o currículo atual não permite um ensino orientado para o projeto e não estimula a capacidade de resolver problemas que fomentem o knowhow, que é "um tipo de saber que não pode ser codificado e não pode ser adquirido mediante métodos discursivos" (Ibid.). 
Dessa forma, o projeto é uma atividade que deve ser praticada durante a graduação, pois não é possível explicar ou ensinar tal como uma disciplina de caráter descritivo. Em outras palavras, o ato de projetar é uma atividade altamente complexa, que envolve uma grande quantidade de conhecimento tácito, pode ser aprendida, mas precisa ser praticada, como se pratica um esporte ou se toca um instrumento musical (LAWSON, 2011).

Oxman (2004) comenta que há certa ingenuidade no ensino de projeto, que se baseia na crença de que quanto mais conhecimento é transmitido a um aluno, mais habilidade para o projeto ele terá. Um professor de projeto sabe que o conhecimento não está diretamente relacionado às habilidades que o aluno desenvolverá, pois há uma grande diferença entre conhecimento, competência e habilidade. Competência em design não é medida pela quantidade de conhecimento adquirido, mas pela capacidade de saber onde encontrá-lo, qual tipo de conhecimento aplicar em uma determinada situação, e como usá-lo quando necessário.

O professor que, como profissional, faz projeto há determinado tempo, tem o seu modo próprio de trabalho, baseado na sua experiência. Profissionalmente ele provavelmente não segue metodologias a risca, como uma receita, e sim deixa fluir o processo que já internalizou. Ou seja, o professor adquiriu um conhecimento tácito sobre como fazer projeto nos seus anos de experiência. Ao transmitir esse conhecimento para os alunos, ele deve explicitá-lo - isto é, um processo de externalização - e isto muitas vezes se dá como um passo a passo ou uma sequência de etapas com objetivos e prazos bem definidos. O conhecimento tácito para os alunos virá com o tempo e a prática, e é algo absolutamente individual. Oxman (2004) levanta uma discussão sobre as deficiências no ensino de projeto e comenta:

\begin{abstract}
"Ensina-se o que o educador julga ser mais importante, baseando-se em sua própria experiência e conhecimento. $\mathrm{O}$ conhecimento a ser transferido poderá ser implícito e, consequentemente, desarticulado de uma forma explícita. Cada estudante adquire conhecimento de acordo com a sua própria interpretação do processo através do qual ele já passou. Diante do predomínio desse paradigma, há a falta de uma base conceitual alternativa para o ensino de design, ou um método complementar - ou alternativo - para a transmissão do conhecimento" (OXMAN, 2004, p. 66).
\end{abstract}

\title{
3.1. A aquisição do conhecimento para aprendizes e para projetistas experientes
}

Projeto e aprendizagem são atividades correlatas, pois, para ambas, encontrar um novo conceito envolve a busca e a aquisição de novas informações e a criação de conhecimento. De acordo com o documento da Pesquisa de Inovação Tecnológica (PINTEC, 2011) há diversas fontes de informação para a inovação, como: fornecedores, clientes ou consumidores, concorrentes, empresas de consultoria e consultores independentes, universidades e institutos de pesquisa, centros de capacitação profissional e assistência técnica, instituições de testes, ensaios e certificações, licenças, patentes e know-how, conferências, encontros e publicações especializadas, feiras e exposições e redes de informações informatizadas. Além dessas pode-se acrescentar: briefing, repertório pessoal dos designers; experiência anterior; trabalhos precedentes; experimentações, entre outras.

Diante da discussão sobre ensino-apendizagem pode parecer que o conhecimento tácito é o mais importante para a formação do designer como um solucionador de problemas, mas o conhecimento explícito também é importante para 
o projeto. É a aquisição desse conhecimento que compõe a base de pesquisa do projeto. $\mathrm{O}$ conhecimento prático acumulado também se constitui em um repertório organizado de soluções, práticas e técnicas que podem ser adaptados aos casos específicos que aparecem a cada novo projeto (NAVEIRO, 2008). Hertzberger (1991 apud LAWSON; 2011) comenta que nossa memória funciona como um tipo de biblioteca que podemos consultar para solucionar um problema, e que tudo o que absorvemos e é registrado pela mente se soma às ideias já registradas.

Então pode-se concluir que o tempo de experiência do indivíduo promove grandes mudanças na forma como ele adquire, processa e utiliza o conhecimento e também na forma como age. Cross et al (1994) realizaram estudos com estudantes de design de vários níveis de competência, com o objetivo de avaliar o desenvolvimento de habilidades e a complexidade do projeto. Ao final desses estudos, comparando-se os alunos do segundo ano com os do último, percebeu-se que os mais experientes tiveram como resultado soluções um pouco mais criativas que os alunos do segundo ano e que também reuniram mais informações para o projeto. Outro estudo acerca da influência da experiência no projeto foi conduzido por Atman et al (1999), no qual os pesquisadores observaram que os mais experientes não somente fizeram projetos de melhor qualidade, como também coletaram mais informações, desenvolveram mais soluções e percorreram mais vezes as etapas de projeto. Atman et al (1999) concluíram que a experiência é um fator importante para o projeto, pois "quanto mais vemos, experimentamos e absorvemos, mais pontos de referência temos para nos ajudar a decidir em que direção seguir: o nosso arcabouço de referência se expande" (Ibid.). Concentrando-se nas estratégias adotadas na fase de resolução de problemas, Mathias (1993 apud KOKOTOVICH 2007) observou que os designers inexperientes pulam algumas etapas importantes no processo antes de elaborar um conceito, como a de 'Análise da confirmação do problema', e também passam da exploração diretamente para a validação da solução. Isso demonstra claramente que o 'projetar' ainda está sendo internalizado por esses indivíduos, e que impor etapas de um processo não garante bons resultados.

Com o decorrer dos anos de atividade, tanto profissionalmente quanto no ensino, o projetista adquire não somente a prática desta atividade, mas também um vocabulário de soluções projetuais mais amplo, visto que as soluções por ele geradas, mesmo que não cheguem à produção, são guardadas em sua memória e influenciam seu desempenho. Claramente, parte do desenvolvimento da habilidade do projetista encontra-se na acumulação de experiência. Algo que distingue os novatos dos experientes é que os experientes já vivenciaram um grande número de exemplos de problemas e soluções que ocorrem na sua área de atuação. Mas uma competência chave de um expert é a capacidade mental de se distanciar da experiência dos exemplos acumulados, e formar conceitos abstratos pertinentes ao projeto em questão. Experts são considerados capazes de armazenar e acessar informação em blocos maiores do que os novatos, e de reconhecer princípios subjacentes, em vez de focar nas características da superfície de problemas (CROSS, 2004).

Em suma, visto que nossa mente funciona a partir de associações e é alimentada pelas experiências, o projeto e o processo de resolução de problemas serão diferentes entre projetistas iniciantes e experientes, e não somente em relação a soluções melhores. Pode-se então concluir que a prática do projeto leva a um modo mais estruturado de conduzir esse processo - com maior rapidez, dinamismo e 
eficiência -, aumenta gradualmente a capacidade de resolver problemas mais complexos e as soluções desenvolvidas atendem melhor às várias faces do problema proposto.

\section{ATIVIDADE DE PROJETO PELA PERSPECTIVA DA GESTÃO DO CONHECIMENTO}

\subsection{Atividades}

Para melhor embasar a reflexão até aqui apresentada, nesse item alguns dos conceitos de Gestão do Conhecimento abordados serão vistos relacionados a atividades de caráter projetual realizadas no contexto do ensino. Tais atividades foram elaboradas para serem aplicadas com alunos com pouca ou nenhuma experiência em projeto, nos cursos de graduação de Design e Engenharia na Universidade Veiga de Almeida (RJ). A ênfase dessas atividades está no auxílio à internalização do processo de solução de problemas, como base para os projetos que os estudantes farão em outras disciplinas.

Ou seja, o objetivo é que o estudante, como aprendiz, seja capacitado como um solucionador de problemas. Essas atividades geralmente são realizadas na segunda metade do semestre letivo por apresentarem uma complexidade um pouco maior. Antes dessas atividades são realizadas outras que darão base para essa, como por exemplo: exercício de pesquisa de informação em projetos precedentes; aplicação dessas informações na solução de problemas simples; exercícios com ferramentas e técnicas de criatividade. Os trabalhos culminam na construção de um modelo rudimentar, mas que demonstre o seu mecanismo de funcionamento. Não é um modelo de apresentação e não há a necessidade de ser esteticamente bem apresentado. A ênfase é a experimentação, e por isso o tempo do estudante é direcionado para que ele pense na melhor forma de fazer a sua ideia realmente solucionar o problema proposto. Geralmente o professor, em conjunto com os estudantes, define o contexto no qual deverá ser realizada a pesquisa de campo. Como exemplo de contextos utilizados em trabalhos de períodos anteriores, pode-se citar: minimização do desconforto para os usuários do sistema de trens urbanos; otimização das atividades domésticas; melhorias para uma comunidade; automação residencial; auxílio aos serviços de alimentação em grandes eventos; soluções para pontos turísticos da cidade, entre outros.

São os próprios alunos que propõem as possibilidades de atuação, para em seguida enunciar o problema que pretendem solucionar. Esse problema deve ter o porte adequado ao que o grupo é capaz de solucionar. No caso dos trabalhos para o sistema de trens, os estudantes não poderiam sugerir "um novo vagão", "uma nova plataforma", nem mesmo "um assento melhorado", pois o porte dessas propostas inviabilizaria a experimentação. Não devem ser projetos para apresentar em desenho, e sim atividades para compreender mecanismos e internalizar o processo. Desse modo, as propostas versaram em torno de "suporte individual para bolsas"; "sinalizador para assentos reservados para prioridade"; "ferramenta para engraxar sapatos nas estações"; "suporte para celulares e tablets", entre outras.

O tempo de duração depende da complexidade do resultado esperado, para que os alunos tenham tempo necessário para buscar informações, experimentar e internalizar conhecimento. Em média dura de seis a oito semanas. Como a conversão do conhecimento tem caráter individual, estimula-se a formação de grupos com 
estudantes de perfis diferentes, para multiplicar o conhecimento e as habilidades de cada um. Isso porque o conhecimento se multiplica ao ser compartilhado através das discussões, trocas de experiência e observação entre os membros do grupo. (NONAKA; TAKEUCHI, 1997)

Nesse tipo de atividade os professores incentivam que os alunos busquem a informação necessária em diversas fontes, como foi visto no item 3, que podem ser utilizadas no projeto de um novo produto e algumas delas podem ser utilizadas pelos estudantes para sanar suas dúvidas.

\subsection{Modelo}

A partir dos estudos sobre como o processo de solução de problemas é praticado com os estudantes iniciantes sob a ótica da Gestão do Conhecimento, foi pensando um modelo para nortear a elaboração das atividades de solução de problemas. Em respeito às necessidades de cada grupo, não são estabelecidas etapas formais de projeto. Mas para um bom andamento do processo são definidas uma ou dus datas de apresentação das atividades realizadas para troca de informações com a turma (como gates, para situar e evitar a falta de planejamento dos alunos) e as demais datas são destinadas à orientação por grupo. Não há rigidez no controle do desenvolvimento da atividade, e os alunos podem retornar a etapas anteriores sempre que desejarem. É comum os alunos retornarem à pesquisa de campo em outros momentos para esclarecer dúvidas, e isso os auxilia no processo de internalização. Mas, de um modo geral, as atividades envolvem etapas, ações e conceitos da Gestão do Conhecimento, que estão organizados no Quadro1.

A orientação das atividades prioriza a indicação de modos de experimentação e de possíveis fontes de informação, em detrimento de indicar formas de solucionar o problema. Outro fator primordial nesse tipo de atividade é a ênfase no estímulo à autonomia na aquisição de informação e conversão de conhecimento. Os relatos dos estudantes endossam esse fato. Em geral eles afirmam terem ido diversas vezes às lojas de materiais e componentes em busca de auxílio até realmente compreenderem como deveriam configurar e construir o protótipo. Nesse caso, o funcionário é o mestre que orienta os aprendizes. Também é comum recorrerem a técnicos e professores de outras disciplinas, como Física e Ciência dos Materiais, o que reforça também o caráter multidisciplinar da atividade.

A pesquisa deve acompanhar todas as etapas, mas há aquelas em que ela se formaliza, como na Pesquisa de campo e na Pesquisa preparatória para o desenvolvimento das soluções (etapa 3). Pode-se perceber também que a ação "Avaliação da viabilidade" está presente em várias etapas, pois um dos objetivos é se basear nas habilidades que cada membro do grupo já possui para estimular o desenvolvimento de outras.

As primeiras etapas têm predomínio de busca por informações e de conversão de conhecimento explícito em tácito para o estudante. É um processo necessário para prepará-lo para as etapas seguintes, dada a sua inexperiência. Definir o problema é um processo intenso de conversão de conhecimento, pois só se compreende um problema quando é possível solucioná-lo. De fato essa é a etapa mais cansativa, tanto para os alunos quanto para o professor, pois é um momento em que o professor deve ter muito discernimento entre estimular a autonomia e sugerir problemas. Os estudantes empregam muito tempo ajustando o problema até que sejam capazes de solucioná-lo. 
Na construção da alternativa escolhida, a alternância dos modos de conversão se repete, pois há vários processos envolvidos. A construção é o momento de maior experimentação, e isso representa uma intensa internalização até que os alunos de fato compreendam a configuração necessária para a solução. Tanto que é comum alguns grupos sinalizarem a necessidade de rever aspectos do problema.

Quadro 1: Relação entre as ações e os conceitos de Gestão do Conhecimento

\begin{tabular}{|c|c|c|}
\hline Etapas & Síntese das ações & Gestão do Conhecimento \\
\hline 1. Pesquisa de campo & $\begin{array}{l}\text { Observação } \\
\text { Entrevista com os possíveis } \\
\text { futuros usuários }\end{array}$ & $\begin{array}{l}\text { Aquisição de informação } \\
\text { Externalização (usuários) } \\
\text { Internalização (estudantes) }\end{array}$ \\
\hline $\begin{array}{l}\text { 2. Definição do } \\
\text { problema }\end{array}$ & $\begin{array}{l}\text { Verificação do caráter original } \\
\text { Avaliação da viabilidade (tempo, } \\
\text { habilidades dos alunos) }\end{array}$ & Todos os modos de conversão \\
\hline 3. Pesquisa & $\begin{array}{l}\text { Soluções existentes } \\
\text { Materiais, componentes } \\
\text { Possibilidades } \\
\text { Avaliação da viabilidade (tempo, } \\
\text { habilidades dos alunos) }\end{array}$ & $\begin{array}{l}\text { Aquisição de informação } \\
\text { Combinação } \\
\text { Internalização }\end{array}$ \\
\hline $\begin{array}{l}\text { 4. Geração de } \\
\text { alternativas }\end{array}$ & $\begin{array}{l}\text { Desenvolvimento do maior } \\
\text { número possível de soluções }\end{array}$ & Socialização \\
\hline $\begin{array}{l}\text { 5. Escolha da } \\
\text { alternativa }\end{array}$ & $\begin{array}{l}\text { Avaliação do caráter original } \\
\text { Avaliação da adequação ao } \\
\text { problema } \\
\text { Avaliação da viabilidade (tempo, } \\
\text { habilidades dos alunos) }\end{array}$ & $\begin{array}{l}\text { Externalização (entre os grupos) } \\
\text { Combinação }\end{array}$ \\
\hline $\begin{array}{l}\text { 6. Construção da } \\
\text { alternativa escolhida }\end{array}$ & $\begin{array}{l}\text { Aquisição de informação em } \\
\text { diversas fontes } \\
\text { Experimentação das formas de } \\
\text { construção } \\
\text { Escolha dos materiais e } \\
\text { componentes }\end{array}$ & Todos os modos de conversão \\
\hline $\begin{array}{l}\text { 7. Elaboração do } \\
\text { memorial descritivo }\end{array}$ & $\begin{array}{l}\text { Redação com base nas pesquisas } \\
\text { e no desenvolvimento de toda a } \\
\text { atividade }\end{array}$ & $\begin{array}{l}\text { Síntese das informações } \\
\text { adquiridas } \\
\text { Externalização do conhecimento } \\
\text { resultado da atividade }\end{array}$ \\
\hline $\begin{array}{l}\text { 8. Apresentação do } \\
\text { modelo e entrega de } \\
\text { memorial descritivo }\end{array}$ & $\begin{array}{l}\text { Teste dos modelos } \\
\text { Concretização das ideias } \\
\text { Compartilhamento de } \\
\text { experiências com a turma }\end{array}$ & $\begin{array}{l}\text { Externalização } \\
\text { Associação para criação de } \\
\text { conhecimento entre os grupos }\end{array}$ \\
\hline
\end{tabular}

Fonte: Elaborado pelo autor, com base na pesquisa realizada

A geração de alternativas é um modo de socialização, pois muitas vezes os desenhos servem como a representação de ideias que os alunos não conseguem expressar com palavras, mas conseguem demonstrar visualmente. Quando os colegas conseguem compreender as ideias, são capazes de acrescentar as suas, aperfeiçoandoas e fazendo associações. 
Nas últimas etapas há o predomínio da externalização, pois é quando os alunos devem converter o conhecimento tácito que adquiram durante toda a atividade em explícito, para que seja possível compartilhar com os colegas e o professor.

\section{CONSIDERAÇÕES FINAIS}

Questões referentes ao ensino de design são lançadas desde que há cursos de design. Apesar dos esforços dos pesquisadores, seja propondo reflexões ou indicando diferentes caminhos que podem ser seguidos, tais lacunas não foram fechadas. E crêse que não há a pretensão de fechá-las. Pois sempre haverá indivíduos, necessidades, possibilidades e cenários diferentes. Naturalmente esse trabalho também não pretende esgotar a discussão sobre a importância da informação e do conhecimento para o campo do design. Mas acredita-se que o objetivo de aproximar o estudante da prática de um solucionador de problemas foi alcançado.

Nesse trabalho foi visto um modelo para desenvolvimento de atividades de solução de problemas baseado nos conceitos da Gestão do Conhecimento. Essa reflexão leva a vários caminhos, como a premissa de que as disciplinas de projeto e as suas correlatas deve ser, então, a capacitação do aprendiz para que ele, aos poucos, se torne o agente da prática e adquira cada vez mais autonomia e eficiência no seu ofício de solucionador de problemas, em vez de insistir na tentativa infundada de transmitir conhecimento. Diante disso, sugere-se o estímulo à busca de informações em todas as etapas, para a qual professor deve orientar a respeito das possíveis fontes, mas evitar oferecer respostas prontas. E, principalmente, promover o contexto necessário para a conversão do conhecimento.

Os estudos do referido grupo de pesquisa seguem em busca de ampliar a compreensão sobre o ensino e a atividade de projetar na vida do estudante e do profissional nos campos do Design e da Engenharia, por caminhos que auxiliem na capacitação de solucionadores de problemas. As atividades realizadas durante 0 semestre letivo se complementam e estão em constante aperfeiçoamento.

Para futuros trabalhos sugere-se a inesgotável revisão dos modos de ensino, mas colocando como foco a formação do estudante em agente do processo. Isso é atemporal e mais forte do que qualquer tecnologia que possa surgir ou novo método que possa ser empregado. Novos métodos e ferramentas auxiliam no processo, mas por si só não transformam aprendizes em projetistas.

\section{REFERÊNCIAS}

ATMAN, Cynthia et al. A comparison of freshman and senior engineering design processes. Design Studies. Vol 20, N² 2, 1999, pp 131-152.

BONSIEPE, Gui. Design como prática de projeto. São Paulo: Blucher, 2012.

BUSCH, Peter. Tacit Knowledge in Organizational Learning. Hershey: IGI Publishing, 2008.

BÜRDEK, B. E. História, Teoria e Prática do Design de Produtos. São Paulo: Blucher, 2006.

CARDOSO, Rafael. Uma introdução à história do design. São Paulo: Blucher, 2008.

CROSS, Nigel; CHRISTIAANS, Henri; DORST, Kees. Design expertise amongst student designers. Journal of Art and Design Education. Vol 13, N 1, 1994, pp 39-56. 
CROSS, Nigel. Expertise in design: an overview. Design Studies Vol 25, n. 5, 2004, pp 427-441.

CROSS, Nigel; CHRISTIAANS, Henri; DORST, Kees. Design expertise amongst student designers. Journal of Art and Design Education. Vol 13, $\mathrm{N}^{\circ} 1,1994$, pp 39-56.

FIGUEIREDO, Cassia Mousinho. ProductMap: uma proposta de organização do conhecimento para o ensino de projeto. 2013. Tese (Doutorado) - Universidade Federal do Rio de Janeiro, Curso de Pós-Graduação em Engenharia de Produção.

FORNASIER, Cleuza Bittencourt Ribas; EMÍDIO, Lucimar de Fátima Bilmaia. Criação do Conhecimento no Projeto Pedagógico do Curso Design de Moda da UEL. Anais do 4은 Colóquio de Moda, Novo Hamburgo, 2008.

KOKOTOVICH, V. Problem analysis and thinking tools: an empirical study of nonhierarchical mind mapping. Design Studies. Vol. 29, N 1, 2007, pp 49-69.

LAWSON, Bryan. Como arquitetos e designers pensam. São Paulo: Oficina de Textos, 2011.

MALDONADO, Tomas. Design Industrial. Tradução: José Francisco Espadeiro Martins. Lisboa: Edições 70, Arte e Comunicação, 1991.

MULLER, Wim. Order and Meaning in Design. Purdue University Press, 2001.

NAVEIRO, Ricardo Manfredi. Engenharia do Produto. In: BATALHA, M.O. Introdução à Engenharia de Produção. 1ed. Rio de Janeiro: Elsevier, 2008.

NAVEIRO, Ricardo Manfredi. Knowledge Management in Product Design: The BAJA Project. 21st International Conference on Production Research, ICPR, Stuttgart, 2011.

NONAKA, Ikujiro. The Knowledge-Creating Company. Harvard Business Review, November/December 1991, pp 96-104.

NONAKA, Ikujiro; TAKEUCHI, Hirotaka. Criação de conhecimento na empresa. Rio de Janeiro: Elsevier, 1997.

OXMAN, Rivka. Think-maps: teaching design thinking in design education. Design Studies. Vol 25, N 1, 2004, pp 63-91.

PINTEC. Pesquisa de Inovação 2011, Instituto Brasileiro de Geografia e Estatística (IBGE), Rio de Janeiro, 2013. Disponível em: <http://www.pintec.ibge.gov.br/ downloads/pintec2011\%20publicacao\%20completa.pdf>. Acesso em 10/11/2015.

SETZER, Vladimir. Dado, Informação, Conhecimento e Competência. In: SETZER, Vladimir. Os Meios Eletrônicos e a Educação: Uma Visão alternativa. São Paulo: Editora Escrituras, Coleção Ensaios Transversais, Vol. 10, 2001.

SVEIBY, Karl Erik. A nova riqueza das organizações - gerenciando e avaliando patrimônios de conhecimento. Rio de Janeiro: Campus, 1998.

TEIXEIRA, Fábio; SILVA, Régio; SILVA, Tânia Koltermann. Um sistema on-line para o design de produtos. 9o Congresso Brasileiro de Pesquisa e Desenvolvimento em Design. São Paulo: Blücher e Universidade Anhembi Morumbi, 2010. 